\title{
Revisiting pyroplastic deformation. Application for porcelain stoneware tile bodies
}

E. Sánchez ${ }^{(\mathrm{a})}$, V. Sanz ${ }^{(\mathrm{a})}$, E. Cañas ${ }^{\left(\mathrm{a},{ }^{*}\right)}$, J. Sales ${ }^{(\mathrm{b})}$, K. Kayacı $^{(\mathrm{c})}$, M.U. Taşkıran $^{(\mathrm{c})}$, Ü.E. $A n 11^{(\mathrm{c})}$, Ş. Türk ${ }^{(\mathrm{c})}$

(a) Instituto de Tecnología Cerámica (ITC), Universitat Jaume I, 12006, Castellón, Spain

(b) GEA CERAMICA S.L., Castellón, Spain

(c) Kaleseramik Canakkale Kalebodur, Çan, Turkey

Enrique Sánchez Vilches

Email: enrique.sanchez@itc.uji.es

Vicente Sanz Solana

Email: vicente.sanz@itc.uji.es

Eugeni Cañas Recacha*

Telephone number: (+34) 964342424

Email: eugeni.canas@itc.uji.es

Fax number: (+34) 964342425

Juan Sales Gil

Email: juansalesgil@gmail.com

Kagan Kayaci

Email: kagankayaci@kale.com.tr

Ugur Taskiran

Email: ugurtaskiran@kale.com.tr

Ümit Anil

Email: umitenginanil@kale.com.tr

Senay Türk

Email: senaykaya@kale.com.tr 


\begin{abstract}
In this research an analysis of firing deformation tendency in porcelain stoneware tile compositions was carried out based on pyroplastic deformation measurements. The effect of the amount and nature of some fluxing additives as well as some process variables were addressed. Firing diagram, pyroplastic deformation and microstructure examination of fired specimens of the different compositions were carried out.

Findings allowed to verify the effect of particle size and unfired bulk density on pyroplastic deformation. Finer particle size and/or higher unfired compactness effectively contribute to reduce pyroplastic deformation. However, the joint effect of particle size and bulk density differs from that observed with more fluxing (redware) floor tile compositions. At compositional level, the effect of some alkaline-earth containing fluxing compounds on the pyroplastic deformation was observed. Thus, Magnesite showed a high fluxing efficiency with moderate deformation while Dolomite displayed a detrimental effect on both densification range and pyroplastic deformation.
\end{abstract}

Keywords: Traditional ceramics; Milling; Firing; Pyroplasticity; Structural applications

\title{
1. Introduction
}

Pyroplastic deformation encompasses a class of defects associated with most traditional ceramic products since their sintering process takes place by developing a significant presence of liquid phase. The problem fundamentally affects those products characterized by a high degree of densification in which their final open porosity is very low or nearly zero. Thus, products such as porcelain, whitewares, clinker, vitrified tiles, etc. undergo this type of deformations owing to the liquid phase developed inside the piece during firing [1,2]. As a consequence, at a given temperature which is very depending on the body composition, the ceramic material no longer behaves as rigid solid and, if a mechanical stress is applied, a permanent deformation called pyroplastic deformation takes place $[3,4]$. The degree of deformation depends on the apparent viscosity of the system, which has to do with the amount of liquid phase and its viscosity as well as with the mechanical stress applied. However, the effect of the "skeleton" of crystalline phases dispersed in the glassy matrix also plays a significant role. Thus, as reported by dos Santos et al. [5], undissolved quartz represents an important variable governing the pyroplastic deformation whereas mullite crystals also can play a role [6]. Research on pyroplastic deformation phenomenon is abundant, nevertheless it has mainly focused on whitewares 
products (tableware, sanitaryware, porcelain, etc) due to the long tradition of these ceramic materials worldwide $[7,8]$.

More than 25 years ago Escardino et al. [9], from Instituto de Tecnología Cerámica in Castellón, Spain, published a reference paper on pyroplastic deformation in tiles. The paper addressed the deformation of redware floor tiles, typically produced in Spain. Due to the highly fluxing behaviour of redware clays, pyroplastic deformation represents a very common problem during the firing of this type of floor tiles. In that paper the authors applied for the first time the pyroplastic index to assess the impact of process variables, mainly particle size distribution and unfired bulk density on pyroplastic deformation. Thus, the paper highlighted the importance of increasing unfired body bulk density and decreasing composition particle size when impervious tiles are to be manufactured.

From that time on, many things have changed in the context of tile product manufacturing. Nowadays, porcelain stoneware, a very low porosity floor tile, is the most demanded product for use in flooring surfaces, but at the same time, it is becoming important to incorporate in other applications such as ventilated facades. The spectacular growth that the manufacture of porcelain stoneware has undergone in the last years deals with its good technical and functional performance associated to the impervious feature of the sintered product, together with the great technological advance that the ceramic tile manufacturing sector is experiencing [1]. Consequently, porcelain stoneware tiles account for more than $30 \%$ of the total floor tile production in the world.

During the first period of porcelain stoneware tile manufacturing in the last decade of last century, pyroplastic deformation was not a serious processing problem compared with other more fluxing compositions such as that of the above mentioned redware floor tile. Porcelain stoneware tile starting composition is made from a triaxial mixture of clay or kaolin, quartz, and feldspar. The clay fraction helps forming by providing plasticity and dry mechanical strength during processing and develops mullite and mainly glassy phase when fired. Feldspars develop glassy phase at low temperatures (sodium feldspar being mainly used), assisting the sintering process, and enabling virtually zero $(<0.5 \%)$ open porosity and a low level of closed porosity $(<10 \%)$ to be achieved. Quartz promotes thermal and dimensional stability thanks to its high melting point [10]. Therefore, a high viscous, silica-rich liquid phase develops which is less prone to deform by pyroplasticity. During the firing reactions in typical industrial kilns (single layer rollers kiln) the tile must retain its dimensional characteristics as it advances through the kiln. However, it has become increasingly difficult due to the recent innovations in porcelain stoneware tile 
manufacture, such as thin thicknesses, very large formats and faster firing cycles. Pyroplastic deformation can already be visible at the kiln exit as a small collapse at the tile edges produced during the soaking time at the maximum firing temperature. The body composition and the process parameters should be therefore carefully selected, so as to achieve low porosities at short firing cycles without deformation of the tile.

Despite the existence of some studies on porcelain stoneware tiles reporting the relationship between the content and nature of the glassy phase and the sintering rate $[3,4,6]$ research on pyroplastic deformation in this type of ceramic tiles is much more recent and scarce. And most of these studies focused on connecting compositional features of the starting bodies with pyroplastic deformation (pyroplasticity index). Thus, Bernandin et al. [11] used a mixture design to formulate porcelain stoneware tile compositions resistant to pyroplastic deformation. By statistical analysis the authors concluded that, as expected, albite from sodium feldspar is the main phase affecting pyroplastic deformation during firing while iron oxide from clay also causes a strong influence. More recently Bresciani and Spinelli examined the factors that determine the tendency of porcelain stoneware tile bodies to undergo pyroplastic deformation [12]. The study presented several porcelain stoneware tile compositions and an instrumental analysis of pyroplasticity. These authors highlighted the effect of the sodium/potassium ratio in the feldspar raw materials as well as the importance of keeping a minimum quartz content in the fired body which acts as skeleton for the piece microstructure. Moreover, the authors insist on the need to use an appropriate firing cycle with relation to the size/thickness ratio of the manufacturing tile. In a more recent paper, L. dos Santos et al. [5] compared the pyroplastic deformation of porcelain stoneware tile bodies obtained from wet and dry milling. On one hand the paper emphasized the importance of the combination of micronized quartz and feldspar to optimize sintering rate without compromising the planarity of the tile. On the other hand, the paper also showed the influence of tile microstructure homogeneity on pyroplastic deformation. Nevertheless, the effect of process variables such as unfired bulk density and body particle size distribution has not been addressed in the literature on porcelain stoneware tiles.

Another is the common practice in the manufacturing of porcelain stoneware tiles deals with the use of highly fluxing additives to enhance sintering rate such as alkaline-earth containing raw materials (calcium carbonate, magnesite, dolomite, talc, etc.). The addition of this type of materials produces an expected decreasing of sintering temperature together with a more or less accentuated shortening of the firing range as a 
consequence of the decreasing in the viscosity of the glassy phase associated with the incorporation of the alkaline-earth oxide in the melting. For this same reason, an effect of alkaline-earth fluxing material on the pyroplastic deformation should be expected. However, this effect has not been addressed in the literature while the empiric approach in the industrial practice has been long prevailing.

From the above it can be inferred that, due to the lack of research activity on pyroplastic deformation in porcelain stoneware tiles as well as the growing interest on firing deformation problems in this type of products, there is a need to raise a study to shed light on this subject. On one hand, this research will address the effect of the main process variables in porcelain stoneware tile manufacture, i.e. body particle size and unfired bulk density of the pressed tile on the tendency to deformate by pyroplasticity. The interaction of both variables must be considered. On the other hand, the paper will also analyze the effect of different alkaline-earth raw materials used in the industrial practice on this same tendency. The final objective of the research is to contribute to establish a more robust body composition and process conditions for manufacturing large format porcelain stoneware tiles without firing deformations.

\section{Materials and methods}

Typical raw materials used in the industry to manufacture porcelain stoneware tiles were used: kaolinitic clay, sodium feldspar and feldsphatic sand. Together with these main raw materials, alkaline-earth fluxing additives were used: Calcite (C), Dolomite (D), Magnesite (M) and Talc (T). Table 1 and figure 1 show the mineralogical and chemical composition of these raw materials determined by X-ray diffraction (XRD) (Advance diffractometer, Bruker Theta-Theta, Germany) and X-ray fluorescence (XRF) (AXIOS,PANalytical, The Netherlands), respectively. For the XRD analysis, the raw materials were dry milled by hand to obtain a powder sample which was analysed with $\mathrm{Cu} \mathrm{K} \alpha$ radiation $(\lambda=1.54183 \AA)$, employing a generator setting of $30 \mathrm{kV}$ and $40 \mathrm{~mA}$ and collecting the data in $2 \theta$ range of $10-80^{\circ}$ with a step size of $0.02^{\circ}$ and a scanning speed of $0.5 \mathrm{~s} \mathrm{step}^{-1}$. In the case of XRF analysis, the raw materials were dry milled in tungsten mill and dried to remove the humidity until a constant weight. After that, a pearl was synthesised with the dry sample, whose composition was assessed in the above mentioned XRF spectrometer provided with a $\mathrm{Rh}$ anode tube, and $4 \mathrm{~kW}$ power. Certified reference materials were used to guarantee the measurements traceability. Chemical analyses of carbonates (C, D and M samples) are omitted since they were almost pure substances (> 
99\% purity). The DTA-TGA tests were also carried out for fluxing materials. The tests were performed in a thermobalance (TGA/STDA 815e, Mettler Toledo, The USA) at a heating rate of $10^{\circ} \mathrm{C} / \mathrm{min}$.

From these raw materials, a standard composition made up of clay (40 wt $\%$ ), sodium feldspar (35 wt \%) and feldesphatic sand (25 wt\%) was formulated. From this composition some batches incorporating different proportions of the alkaline-earth additives were prepared. A wide variation of the proportion of each fluxing additive was assessed in an attempt to provoke significant changes in the sintering behavior of the standard composition.

Table 1. Mineralogical composition of the raw materials used

\begin{tabular}{|c|c|c|c|c|}
\hline \multirow{2}{*}{$\begin{array}{c}\text { Raw } \\
\text { materials }\end{array}$} & Clay & Feldspar & $\begin{array}{c}\text { Feldspathic } \\
\text { sand }\end{array}$ & Talc \\
\hline \multirow{2}{*}{$\begin{array}{c}\text { Mineralogical } \\
\text { phases }\end{array}$} & $\mathrm{K}$ & $\mathrm{A}$ & $\mathrm{Q}$ & $\mathrm{T}$ \\
\cline { 2 - 5 } & $\mathrm{Q}$ & $\mathrm{I}$ & $\mathrm{K}$ & $\mathrm{D}$ \\
\cline { 2 - 6 } & Others & Q & $\mathrm{O}$ & $\mathrm{Ch}$ \\
\hline $\mathrm{A} \rightarrow$ Albite & $\mathrm{Q} \rightarrow$ Quartz & Others & - \\
$\mathrm{Ch} \rightarrow$ Chlorite & $\mathrm{T} \rightarrow$ Talc & $\mathrm{D} \rightarrow$ Dolomite \\
$\mathrm{O} \rightarrow$ Orthoclase & $\mathrm{K} \rightarrow$ Kaolinite & $\mathrm{I} \rightarrow$ Illite + Mica \\
\hline
\end{tabular}



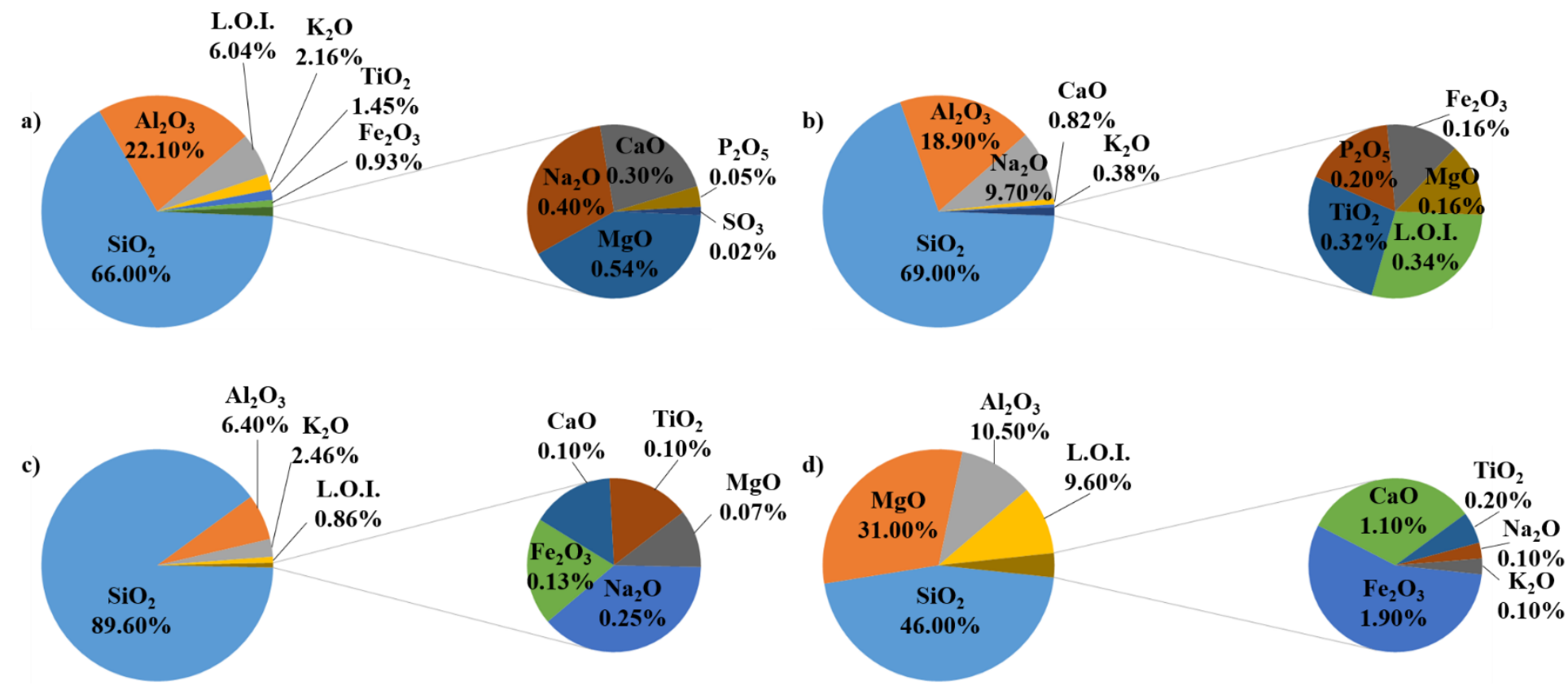

Figure 1. Chemical composition in wt $\%$ of the raw materials used: a) clay, b) feldspar, c) feldesphatic sand and d) talc

Figure 2 shows the addition range in $\mathrm{wt} \%$ to the standard composition for each fluxing material as well as the corresponding provided fluxing oxide content in molar basis. The procedure followed to prepare the ceramic powder from all the compositions has been explained elsewhere $[9,13,14]$. A fixed grinding oversize was established for all the compositions in order to keep constant the particle size distribution of pressing powders. This residue was $6 \mathrm{wt} \%$ over $40 \mu \mathrm{m}$ sieve.

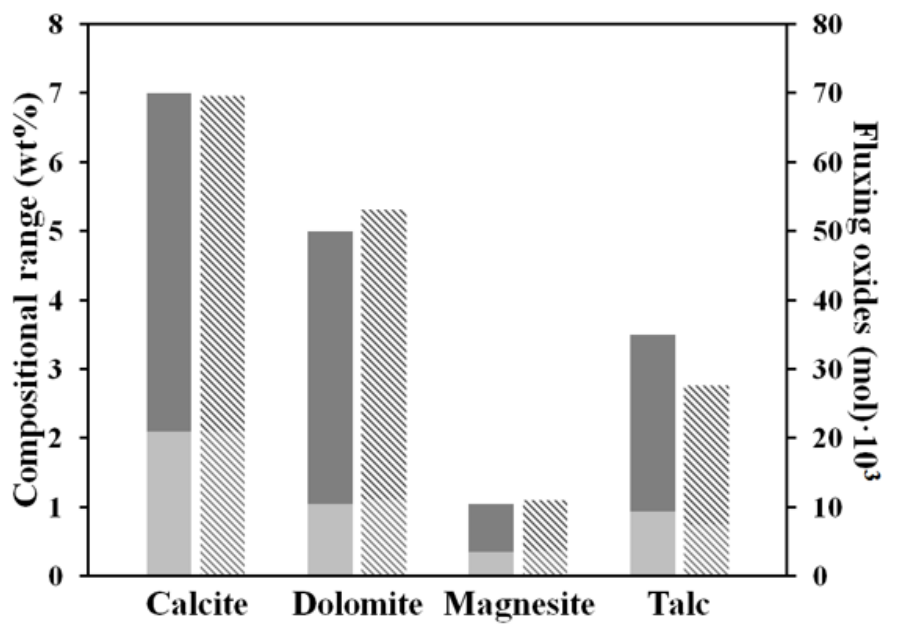

Figure 2. Addition range in wt $\%$ to the standard composition for each fluxing material (filled bars) as well as the corresponding provided fluxing oxide content in molar basis (striped bars) 
With a view to assessing the effect of particle size of porcelain stoneware tile body composition, the standard (STD) mixture was ground in a laboratory, planetary mill at three different residues over $40 \mu \mathrm{m}$ sieve: 1, 3 and $6 \mathrm{wt} \%$ (hereafter referred as 1-STD, 3-STD and 6-STD respectively). Figure 3 displays the particle size distribution curves for these three compositions.

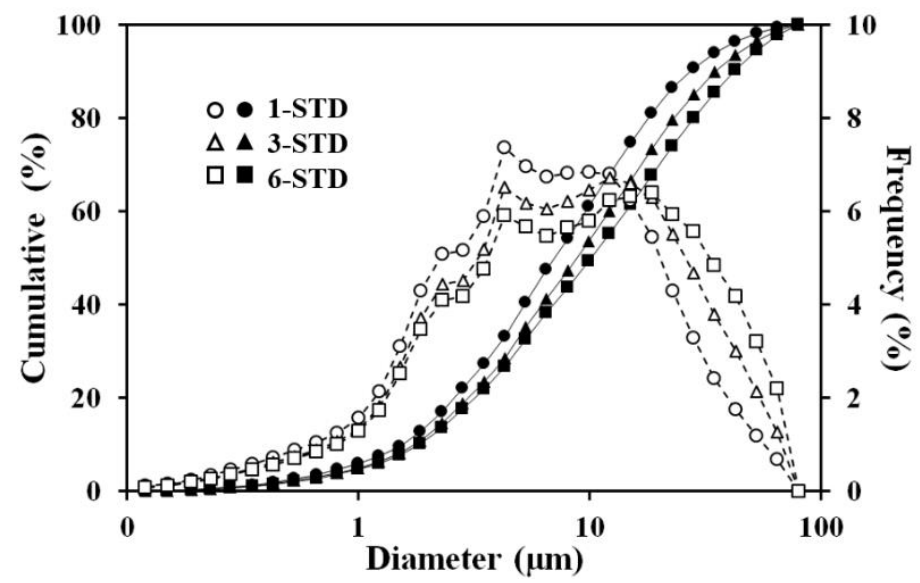

Figure 3. Particle size distribution curves of the standard composition ground at three different residues over $40 \mu \mathrm{m}$ sieve: 1, 3 and $6 \mathrm{wt} \%$ (1-STD, 3-STD and 6-STD compositions). Filled points correspond to cumulative distribution and hollow points to frequency distribution

To determine pressing and firing behaviour, cylindrical test pieces about $5 \mathrm{~mm}$ thick and $50 \mathrm{~mm}$ in diameter were formed. In addition, test pieces measuring $80 \times 20 \times 6 \mathrm{~mm}$, were prepared to determine the pyroplasticity index. Regardless the geometry of the pieces, the bodies were formed at a moisture content of $6 \%$ (on a dry basis) by uniaxial pressing at a pressure of $400 \mathrm{~kg} / \mathrm{cm}^{2}$. In some cases, this pressing pressure was varied (increased or decreased) when compositions with different particle size or fluxing additive had to be formed at constant bulk density. After they had been pressed, the test pieces were sintered in an electric laboratory kiln with a heating ramp of $70{ }^{\circ} \mathrm{C} / \min$ between $25{ }^{\circ} \mathrm{C}$ and 500 ${ }^{\circ} \mathrm{C}$, and $25{ }^{\circ} \mathrm{C} / \mathrm{min}$ from $500{ }^{\circ} \mathrm{C}$ to the respective peak firing temperature. The residence time at peak firing temperature was 6 minutes. The peak firing temperatures encompassed the range $1170-1240{ }^{\circ} \mathrm{C}$ range, depending on each composition. The measurements of the dry and fired dimensions of the test pieces were made using a slide calliper.

The technological properties of the fired test pieces were evaluated by performing the following tests: bulk density and water absorption. Bulk density was measured using the 
mercury displacement method with an uncertainty of $\pm 0.002 \mathrm{~g} / \mathrm{cm}^{3}$. Water absorption was performed by the impregnation method under vacuum with an uncertainty of \pm 0.05 $\%$. In this method, the water uptake is calculated by measuring the gain in test piece weight, after being subjected to a vacuum pressure of $91 \mathrm{kPa}$ for 30 minutes, then being submerged in water and remaining in it at atmospheric pressure for 15 minutes.

In order to determine the tendency to deform by pyroplasticity, prism-shaped test specimens were fired at different maximum temperatures in an electric laboratory kiln. To perform the firing, the test specimens only rested on their two ends (Figure 4), thus allowing them to deform in the course of firing [9]. Their tendency to deform by pyroplasticity was evaluated by calculating the pyroplasticity index (PI) from equation 1.

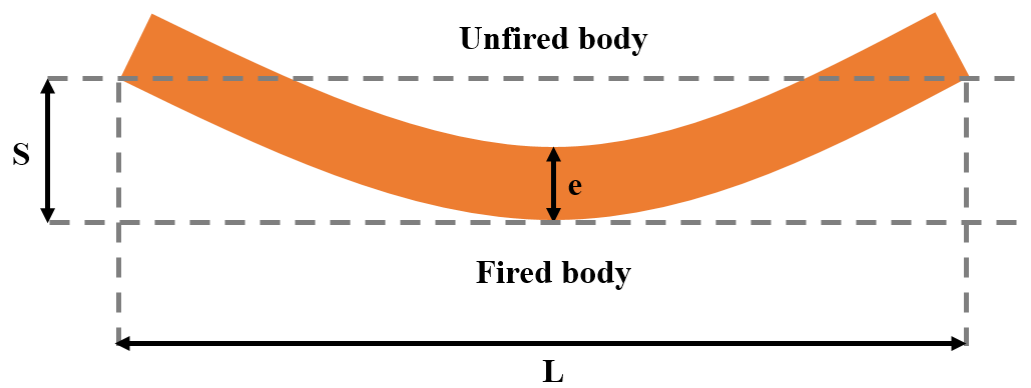

Figure 4. A scheme of the experimental method to calculate the pyroplasticity index (PI). "L" is the body length, "s" corresponds to the sag (body firing deformation) and "e" is the body thickness

$$
P I=\frac{4 \cdot e^{2} \cdot s}{3 \cdot L^{4}} \quad \text { (eq.1) }
$$

Finally, microstructure of some polished cross-section fired samples were obtained by field emission gun environmental scanning electron microscope (FEG-ESEM) (Quanta 200FEG, FEI Company, USA). Porosity of polished samples was also determined by image analysis (MicroImage) of SEM micrographs from an average value of 10 observations (pictures).

\section{Results and discussion}

\subsection{Thermal behaviour of added fluxing materials}

Figure 5 shows the DTA-TGA tests results for the four fluxing materials used in this research. As observed, for carbonates samples (calcite, dolomite and magnesite) the thermal behaviour corresponds to that of almost pure substances, exhibiting exclusively the endothermic peaks associated to the carbonate decomposition, one peak for $\mathrm{C}$ and $\mathrm{M}$ 
samples and two peaks for D. Besides, comparing the three carbonates, it is noticeable the much lower decomposition temperature of magnesite which can make the gas removal during a fast firing cycle easier. Unlike the carbonates, the $\mathrm{T}$ sample displays a more complex thermal behaviour as a consequence of the existence of other minerals in the sample together with talc (Figure 1). Thus, apart from the water removal from talc structure observed at $964{ }^{\circ} \mathrm{C}$ (the fourth peak in DTA-TGA curves), there are other two decompositions corresponding to chlorite mineral (first peak) and dolomite (second and third peaks).
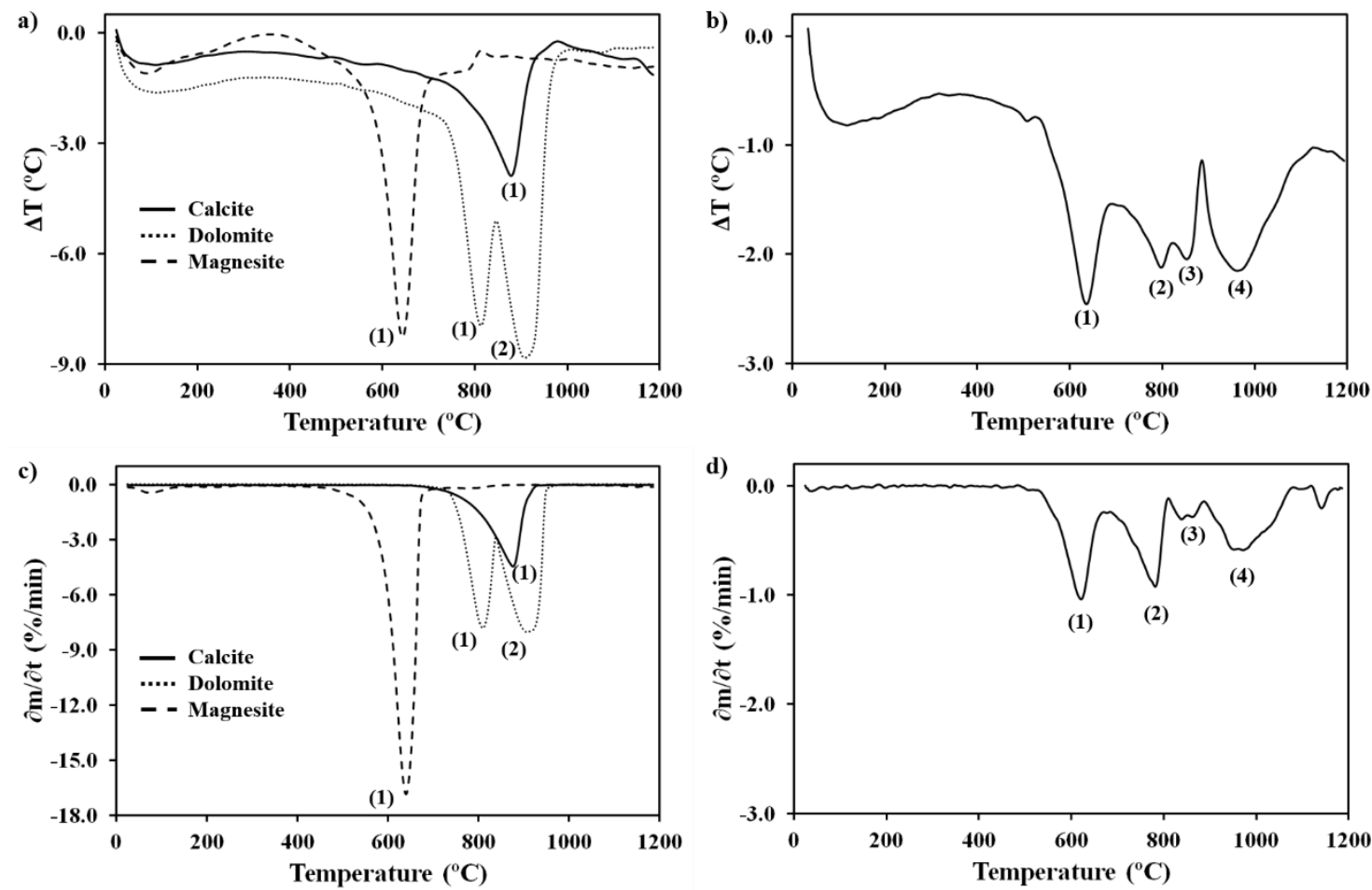

Figure 5. DTA-TGA curves for the four fluxing materials used in this research: a and c DTA and TGA curves for C, D and M samples; $b$ and d DTA and TGA curves for T sample

\subsection{Influence of main process variables (composition particle size and unfired} body bulk density) on firing behaviour and pyroplastic deformation

Figure 6 plots the firing diagram (fired bulk density and water absorption versus firing temperature) for the STD composition milled at the three oversizes of 1, 3 and $6 \mathrm{wt} \%$ (1STD, 3-STD and 6-STD respectively). To eliminate the effect of the particle size distribution on particle packing when pressing this diagram was obtained for pressed bodies formed at constant unfired bulk density of $1.94 \mathrm{~g} / \mathrm{cm}^{3}$. Thus, for 1-STD higher pressure than $400 \mathrm{~kg} / \mathrm{cm}^{2}$ was necessary while the contrary was true for 6-STD 
composition. As expected, a finer particle size gives rise to a decrease of the maximum densification temperature (an increase of sintering rate) as well as the temperature at which the water absorption reaches zero value. Additionally, decreasing particle size also leads to higher densification values. As previously reported, when the particle size decreases an unfired tile microstructure made up of finer pores and higher reactivity (increasing number of contacts between solid particles) develops enhancing densification process and increasing fired bulk density [15].

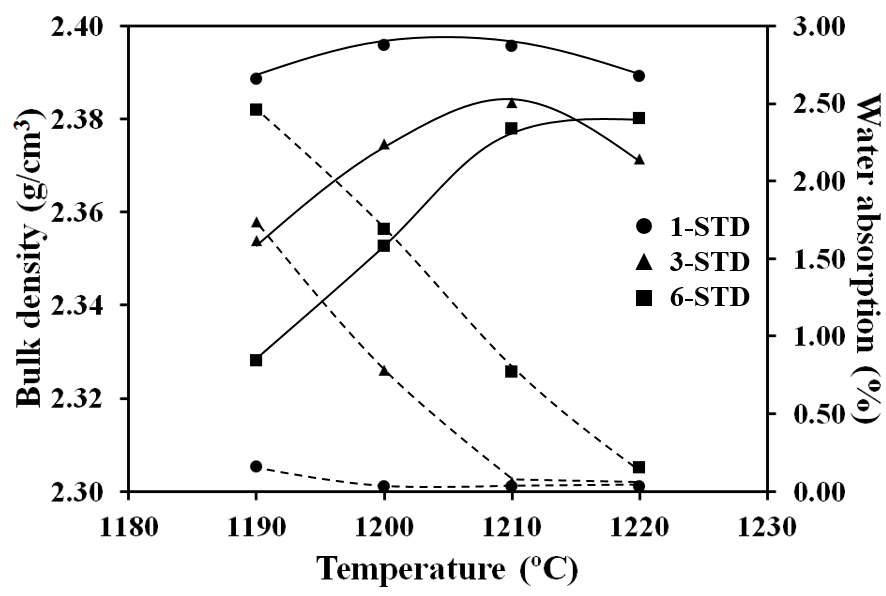

Figure 6. Variation of fired bulk density (continuous curves) and water absorption (dotted curves) versus firing temperature for 1-STD, 3-STD and 6-STD compositions (at a constant unfired bulk density of $\left.1.94 \mathrm{~g} / \mathrm{cm}^{3}\right)$

In order to deepen on this firing behaviour, microstructure of some fired specimens at maximum firing density obtained at different pressing conditions were examined. Figure 7 shows micrographs of 5 samples of two series of fired bodies obtained from 1-STD, 3STD and 6-STD samples. The first series (micrographs a, b and c) corresponds to that of unfired bodies pressed at the same unfired bulk density of $1.94 \mathrm{~g} / \mathrm{cm}^{3}$. The second series (micrographs $\mathrm{d}, \mathrm{b}$ and e) displays fired specimens obtained from bodies pressed at the same pressing conditions (moisture content of $6 \%$ on a dry basis and a pressing pressure of $400 \mathrm{~kg} / \mathrm{cm}^{2}$ ). For this second series, the bulk density obtained after pressing were as follows: $1-\mathrm{STD}=1.90 \mathrm{~g} / \mathrm{cm}^{3}, 3-\mathrm{STD}=1.94 \mathrm{~g} / \mathrm{cm}^{3}$ and $6-\mathrm{STD}=1.97 \mathrm{~g} / \mathrm{cm}^{3}$. As observed in figure 7, the cross-section micrographs corresponding to the first series (samples a, b and c) corroborate the firing behaviour in figure 6: the finer the particle size in the starting composition the higher the fired bulk density (lower fired porosity) is. The effect becomes 
more pronounced when the composition was ground at $1 \mathrm{wt} \%$ reject. However, increasing grinding time also produces narrower particle size distributions (Figure 3) which impair particle packing [16], as deduced from the bulk density values set out above. Thus, for the second series (samples $d, b$ and e), the higher reactivity effect of a finer particle size distribution becomes practically compensated by an impaired unfired bulk density resulting in quite similar fired microstructures as observed in figure 7. To confirm microstructure appreciations in figure 7 , in this same figure a plot with the total porosity values of all these fired specimens obtained by image analysis is also included. Although in general total porosity values are quite low, some conclusions can be inferred. A reduction of this fired porosity is observed when the composition particle size decreases and the unfired bulk density of the starting pressed bodies keeps constant. On contrary, these porosity values confirm the compensating effect of the impaired unfired bulk density when using finer particle size distribution since practically no changes in porosity values were observed in the second series (samples d, b and e). 
a)

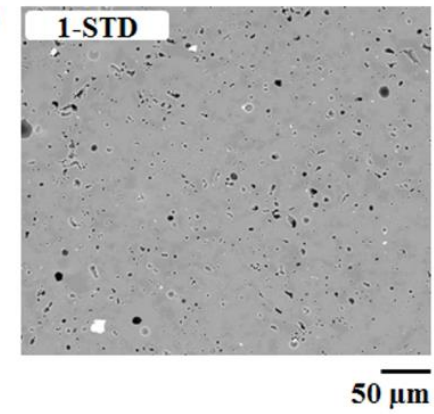

d)

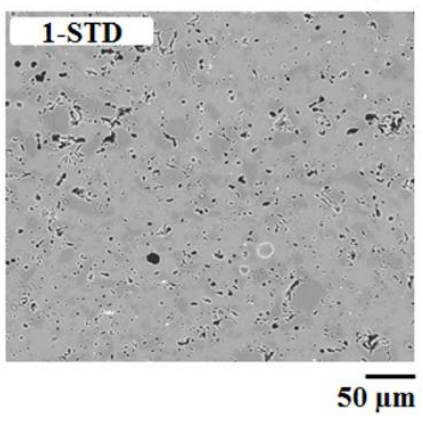

b)

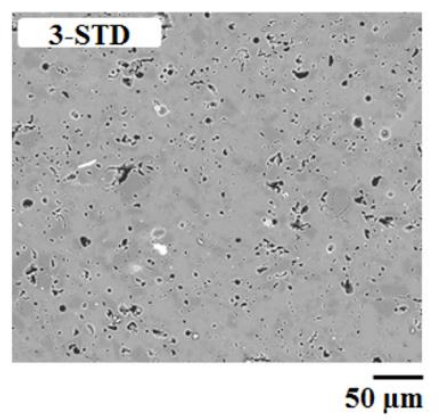

c)

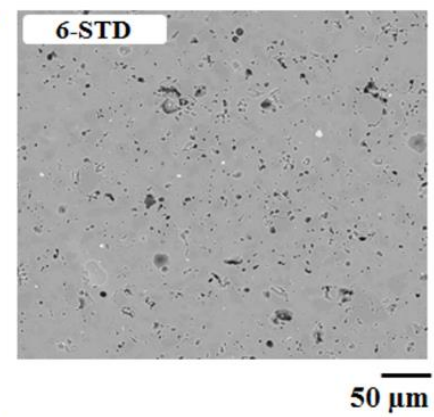

e)

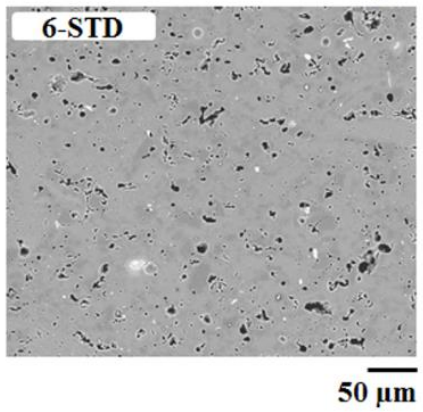

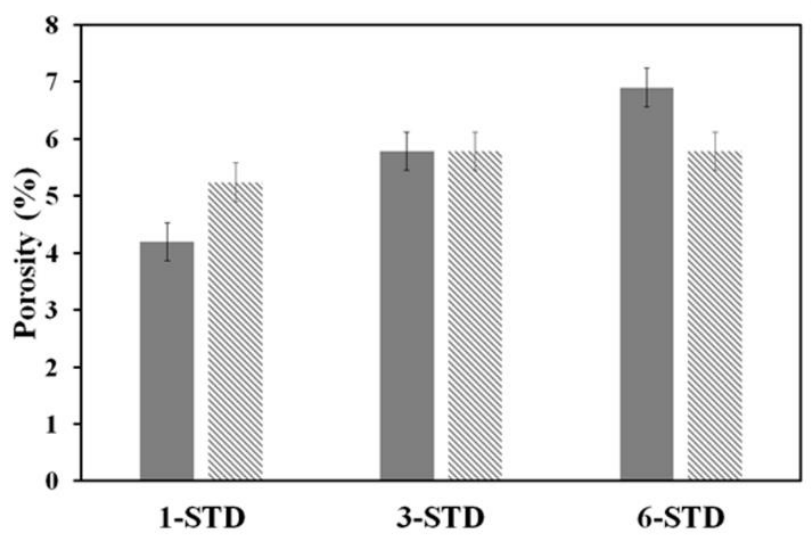

Figure 7. Cross-section micrographs of fired specimens at the maximum firing density of two series of samples obtained from compositions 1-STD, 3-STD and 6-STD: first series (a, b and c) corresponds to samples obtained from bodies pressed at constant bulk density $\left(1.94 \mathrm{~g} / \mathrm{cm}^{3}\right)$ and the second series $(\mathrm{d}, \mathrm{b}$ and e) to samples obtained from bodies pressed at constant pressing conditions. The figure also shows the plot of total fired porosity determined by image analysis for all these fired specimens: filled bars for first series and striped bars for second series

The analysis of the pyroplastic deformation has been done by plotting pyroplastic index against water absorption as suggested by Escardino et al [9]. Figure 8 shows this representation for 1-STD, 3-STD and 6-STD compositions. Due to the interaction of composition particle size on unfired bulk density two types of representation have been drawn: the variation of pyroplastic index with water absorption for bodies pressed at the constant pressing conditions set out above (Figure 8a) and the same plot but for bodies pressed at the constant unfired bulk density of $1.94 \mathrm{~g} / \mathrm{cm}^{3}$ (Figure $8 \mathrm{~b}$ ). As it can be 
observed, all the curves show the expected hyperbolic-like variation (increase) of pyroplastic index as the water absorption decreases. As postulated by these authors with a red-firing floor tile composition, as the temperature rises to obtain low water absorption the densification rate (variation of water absorption with time) by liquid-phase sintering gradually decays while deformation rate (variation of pyroplastic index with time) rapidly grows leading to a strong increment of pyroplastic deformation. On the other hand, as a consequence of the effect of particle size set out above a reduction of pyroplastic deformation (PI) as well as of the slopes of the curve at constant water absorption with increasing grinding time should be expected as reported in the previous research with redware floor tile composition [9]. However, despite the significant differences provoked in the average particle size of the compositions when grinding (Figure 3), PI values for the coarsest particle size composition are much lower than those of the finest particle size composition. In fact, PI values increase according to the following sequence 1-STD > 3STD $>6-S T D$. This is because, as mentioned above, milling time affects to both reactivity of the powder and bulk density of the pressed tiles. Finer particle size decreases firing temperature while the same is true when the pressed tile bulk density rises. Consequently, increasing milling time produces two simultaneous and opposing effects on vitrification temperature and pyroplastic index which explains the unexpected sequence of the curves of pyroplastic trend variation with water absorption shown in Figure 8a. As mentioned, this finding contrasts with that observed for redware floor tile composition in which the particle size effect prevailed over the bulk density effect. To observe these differences, the curves for the redware body at three milling times previously reported [9] have been plotted as dotted lines in the same Figure 8a. This discrepancy between redware floor tile and porcelain stoneware tile bodies can be attributed to the much higher fluxing behaviour of red clays which would compensate the decreasing of unfired bulk density.

These findings can be confirmed when analysing Figure $8 \mathrm{~b}$ where the plot of pyroplastic index versus water absorption was determined for constant bulk density bodies. As it can be observed, when the bulk density in the pressed tiles keeps constant the effect of particle size distribution on pyroplastic index becomes evident. Thus, as it could be expected, decreasing particle size gives rise to a dramatic reduction of the pyroplastic deformation trend, the effect is much more pronounced as the water absorption approaches 0 . Thus, the variation of IP values for a given water absorption follows the expected sequence: 6 - 
STD $>3-$ STD $>1-S T D$. From these findings, it can be easily deduced that the joint effect of coarse particle size and low bulk density can be detrimental for the appearance of pyroplastic deformation problems. The effect of these two processing variables can be summarised as follows. On the one hand, with decreasing bulk density, the number of contacts between particles diminishes, while porosity and average pore size augment causing the tile to attain a certain porosity (water absorption) at higher temperatures and consequently, at lower liquid phase viscosities. On the other hand, at shorter grinding times (coarser particle size), the vitrification rate of the body is impaired as the pore size and the particle size are increased, as a consequence the tile reaches a certain porosity at higher temperatures (lower viscosities). Thus, these results emphasize the importance of particle size and bulk density regarding pyroplastic deformation as well as the need to control these parameters during the manufacturing process. Nevertheless, in the industrial practice, milling time, and consequently, particle size distribution usually is kept constant for the implications that this parameter has on many other process parameters. For this reason, it is much more advisable and easier to act on the pressing bulk density to adjust the firing behaviour of the tile in terms of densification and deformation rate.
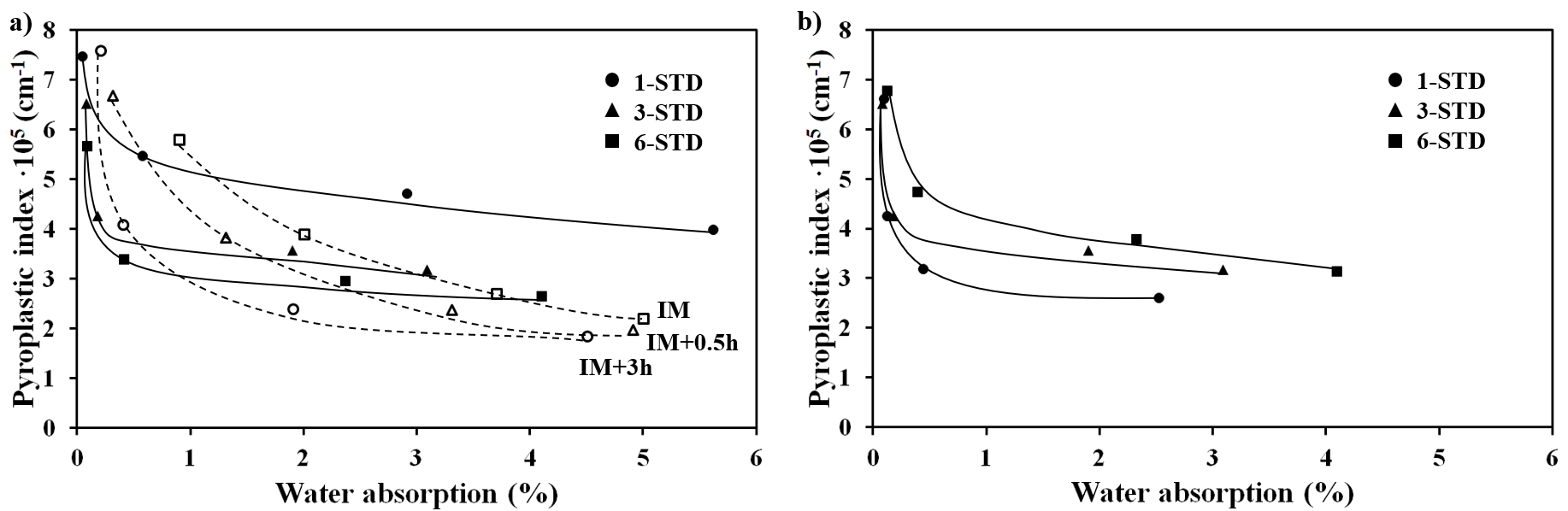

Figure 8. Variation of PI versus water absorption for 1-STD, 3-STD and 6-STD compositions formed at a) the same pressing pressure of $400 \mathrm{~kg} / \mathrm{cm}^{2}$ and b) the same unfired bulk density $\left(1.94 \mathrm{~g} / \mathrm{cm}^{3}\right)$. Dotted curves in the plot correspond to the curves obtained by Escardino et al. [9] with a redware floor tile composition ground at three different milling times (Industrial milling or IM, IM+0.5h and IM+3h) 


\subsection{Influence of the nature and the amount of fluxing additives on firing behaviour and pyroplastic deformation}

Four typical fluxing additives were assessed. Each fluxing material has been tested at three different addition percentages trying to cover the amount used in the industrial practice, and, more interestingly, allowing the composition to reach and overcome the maximum densification state at a reasonable firing temperature. In all the cases, the reference used to denote each composition was as follows: additive initial-weight percentage. Thus, for example, a composition with an addition of $0.7 \mathrm{wt} \%$ of Magnesite is denoted by $\mathrm{M}-0.70$. Moreover, the unfired bulk density was kept constant for all the pressed specimens $\left(1.97 \mathrm{~g} / \mathrm{cm}^{3}\right)$ by modifying the pressing pressure when necessary. Therefore, in the following discussions the effect of this parameter will be disregarded. The firing diagrams for each series of compositions are shown in figure 9. In this figure, the curve corresponding to the standard composition with the same unfired bulk density of $1.97 \mathrm{~g} / \mathrm{cm}^{3}$ (6-STD) is included for the sake of comparison. On observing these graphs, the role of the fluxing material (alkaline-earth oxides) of the four compounds is evident, i.e. in all the cases the addition of the fluxing material shifts, more or less evidently, the firing curves (fired bulk density and water absorption) to the left (lower firing temperatures). On the other hand, maximum firing density is practically not affected for $\mathrm{M}$ and $\mathrm{T}$ compositions while for $\mathrm{D}$ and $\mathrm{C}$ series, specifically for the highest amount of fluxing material addition, maximum firing density and, above all, bulk density curve profiles are strongly altered. It is particularly noticeable the narrowing effect on the densification curves produced by the increasing addition of Dolomite. A reason for this effect is not clear, but probably the porosity increases at relatively high temperature during firing from the decomposition of dolomite (as observed in the DTA-TGA curves in Figure 5) can contribute, in some extent, to this behaviour. Another possible explanation for this shortening of the firing range could be related to a sort of alkalineearth mixing effect from calcium-magnesium mixture similar to that widely explained in glass literature for alkaline oxide mixtures [17]. This effect has been recently reported for $\mathrm{Ca}-\mathrm{Mg}$ silicate glasses, confirming the non-linear evolution of compositional dependence for viscosity in these glasses [18]. Nevertheless, this hypothesis should be confirmed with further research by using some more standard porcelain stoneware tile compositions. In the case of calcite addition, there is a strong impact on densification 
curve for the highest ( $7 \mathrm{wt} \%)$ addition. For this $\mathrm{C}-7.00$ composition maximum firing density is not reached as a consequence of a significant delay in the densification process. As reported elsewhere, increasing addition of calcium supplying raw materials to an alumino-silicate ceramic mixture gives rise to the formation of calcium-based crystalline phases such as anorthite and wollastonite which are responsible for this densification retardation $[19,20]$. In fact, literature shows some reports in which anorthite-based porcelain stoneware compositions were formulated by adding raw materials containing calcium oxide whereas some benefits in mechanical properties as well firing whiteness can be obtained [21-22]. To confirm this, XRD pattern of this $\mathrm{C}-7$ composition was obtained as shown in figure 10. As it can be observed, diffraction peaks of anorthite appears in the sample.
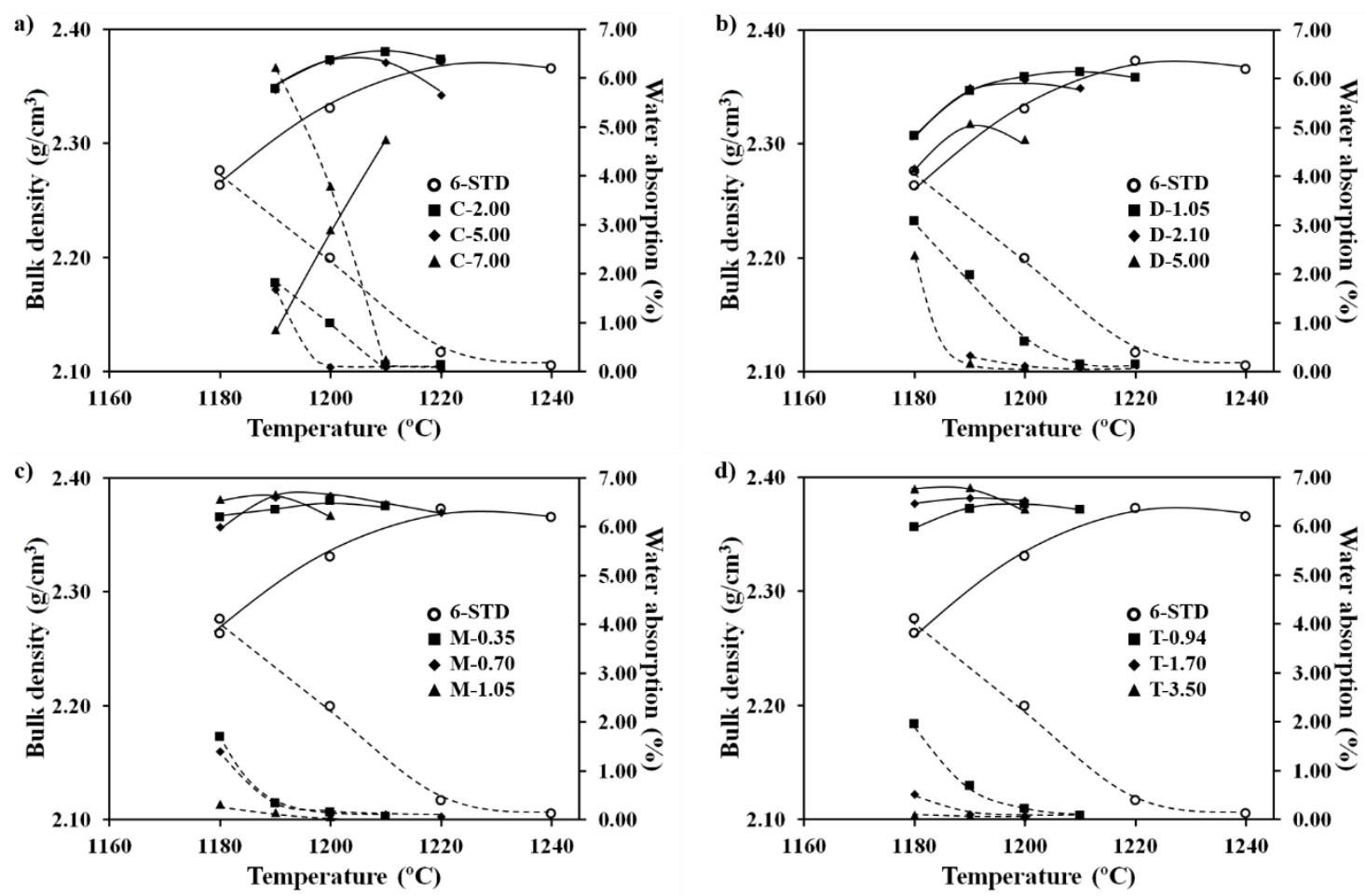

Figure 9. Firing diagrams (variation of fired bulk density and water absorption versus firing temperature) for the four series of compositions with different amounts of the additives: calcite, dolomite, magnesite and talc. Continuous curves for bulk density and dotted curves for water absorption 


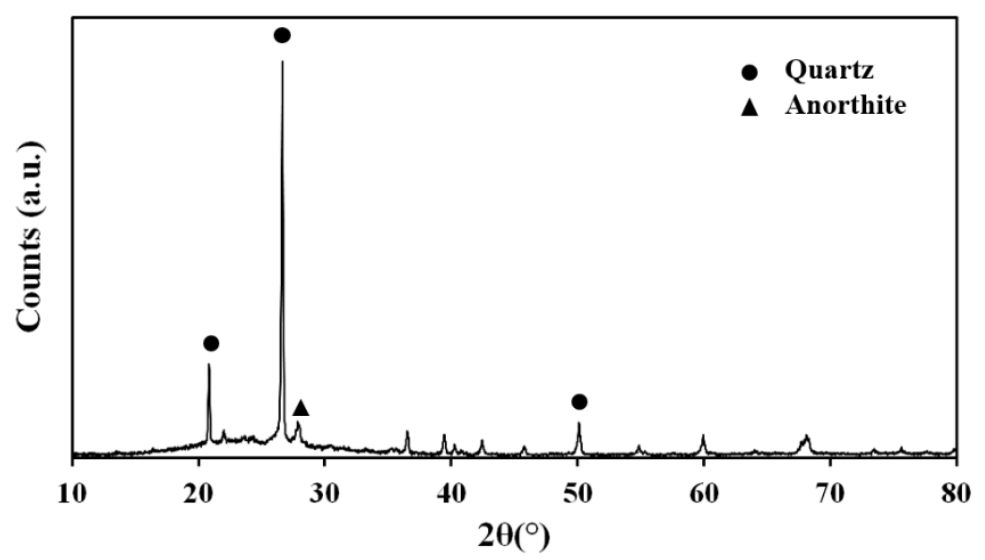

Figure 10. XRD pattern of the fired specimen belonging to the composition C-7.00 ( $7 \mathrm{wt} \%$ of Calcite) fired at the maximum firing density

With regard to the efficiency of the different fluxing materials, a simple observation of the four diagrams allows us to conclude that magnesite leads to the same effect with much lower amount of additive. For a more rigorous comparison, figure 11 displays the fluxing efficiency of these materials in terms of decrease of maximum firing density temperature $(\Delta \mathrm{T})$ per mol addition of fluxing oxide (calcium, magnesium of both oxides). This estimate was done for $2 \mathrm{wt} \%$ addition for Calcite, Dolomite and Talc and $1 \mathrm{wt} \%$ addition for Magnesite. As it can be seen, efficiency of magnesite is much higher than that of the other compounds. From all this information, the additives can be easily ordered according to the decreasing fluxing efficiency as follows: Magnesite $>$ Talc $>$ Dolomite $>$ Calcite.

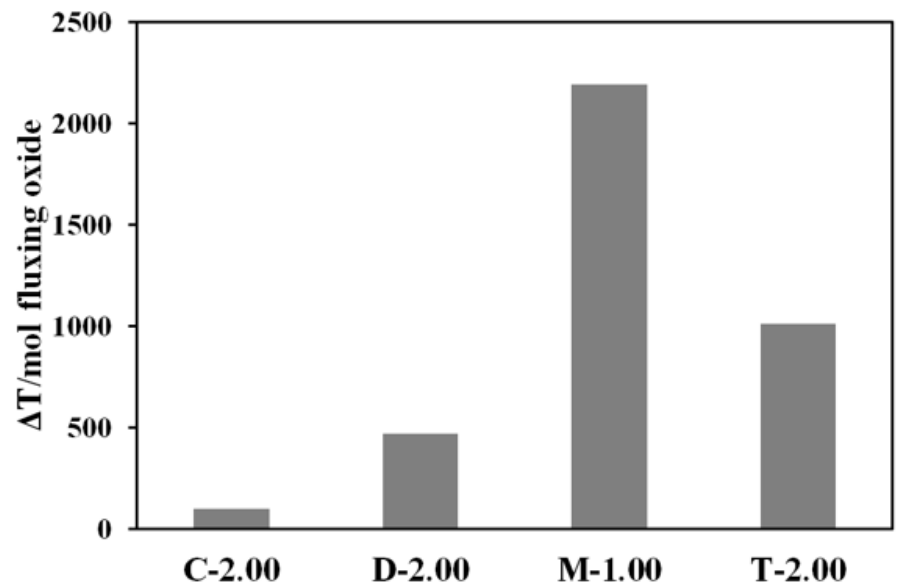

Figure 11. Fluxing efficiency of the four additives (Calcite, Dolomite, Magnesite and Talc) in terms of decrease of maximum firing density temperature $(\Delta \mathrm{T})$ per mol addition of fluxing oxide (calcium, magnesium or both oxides) 
Overall, the fluxing effect observed with the additives used in this work agrees with previous research reported in the literature on porcelain stoneware tiles. Thus, $\mathrm{CaO}$ and $\mathrm{MgO}$ supplying raw materials (calcium carbonate, wollastonite, dolomite or talc) have been proved to reduce in more or less extent the firing temperature as a consequence of the development of increasing glassy phase with lower viscosity $[6,23,24]$. With regard to magnesium compounds, literature shows the great fluxing efficiency of typical magnesium silicate compounds such as talc or chlorite [6,23]. For calcium oxide supply, wollastonite and calcite have been used [20,24]. Regardless the raw material used the transition from a fluxing effect when calcium oxide incorporates into the glassy matrix to silicate crystallisation as the amount of calcium oxide in the starting composition grows has also been reported as set out above. More recently, the use of waste glasses containing alkaline-earth oxides such as calcium, magnesium or barium have confirmed the role of these oxides as efficient fluxing materials in porcelain stoneware compositions [25-27]. However, an estimate of the efficiency of the different fluxing materials is not easily deduced because of the lack of a systematic study whereas the fluxing effect largely depends on the starting body composition (amount of kaolinitic clay, quartz...) as well as processing variables (milling time and unfired body bulk density).

Figure 12a shows the diagram of pyroplasticiy index versus water absorption for all the specimens prepared from the four compositions together with the 6-STD composition. As it can be seen, all the compositions display the variation profile already shown in the previous section, i.e. a hyperbolic-like increase of pyroplasticity as the water absorption approaches zero. At low values of water absorption, typical of porcelain stoneware tiles (below $0.5 \%$ as marked by the shadow area) all the compositions present pyroplasticity values higher than those of the 6-STD composition. For the composition C-5 the effect is minimum at higher water absorptions which is consistent with the lower fluxing efficiency of this additive. On the contrary, the increase in the pyroplasticity index is much higher for the dolomite composition than that of the other three. This finding agrees with the results set out in the firing diagrams where the detrimental effect of dolomite addition on the firing range of the composition was observed. This relationship between 
the firing range shortening effect and pyroplastic deformation has been also reported in previous research with more fluxing tile compositions [9].

Although there are very few works dealing with the compositional effect of porcelain stoneware tile bodies on pyroplastic deformation, previous research confirms the clear relationship between fluxing effect and pyroplastic deformation as reported with spodumene [28], talc [6] and more recently with glass wastes containing alkaline-earth oxides [29]. However, previous research also reveals that the effect of the fluxing compound on pyroplastic deformation depends in great extent on the crystalline phase distribution and microstructure of fired bodies. Consequently, an estimate of the comparative effect on pyroplastic deformation of the different fluxing oxides is not possible.

b)

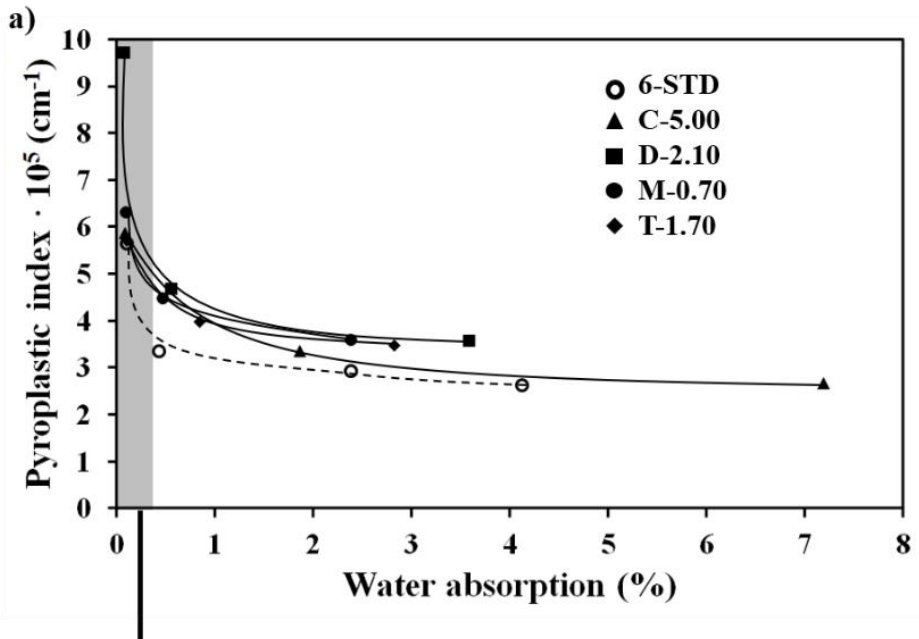

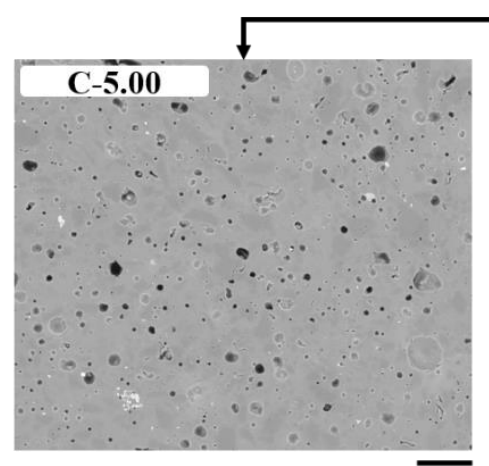

$50 \overline{\mu \mathrm{m}}$

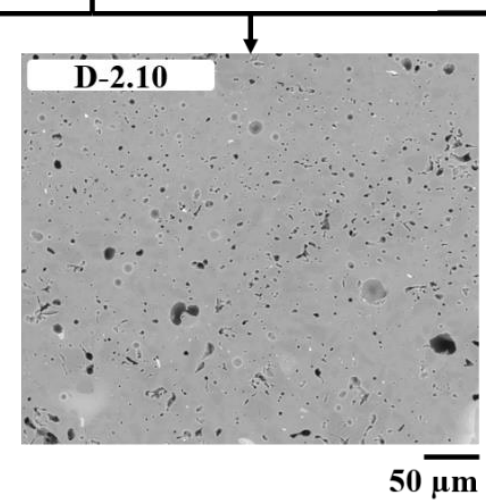

$\mathbf{5 0} \overline{\mu \mathrm{m}}$
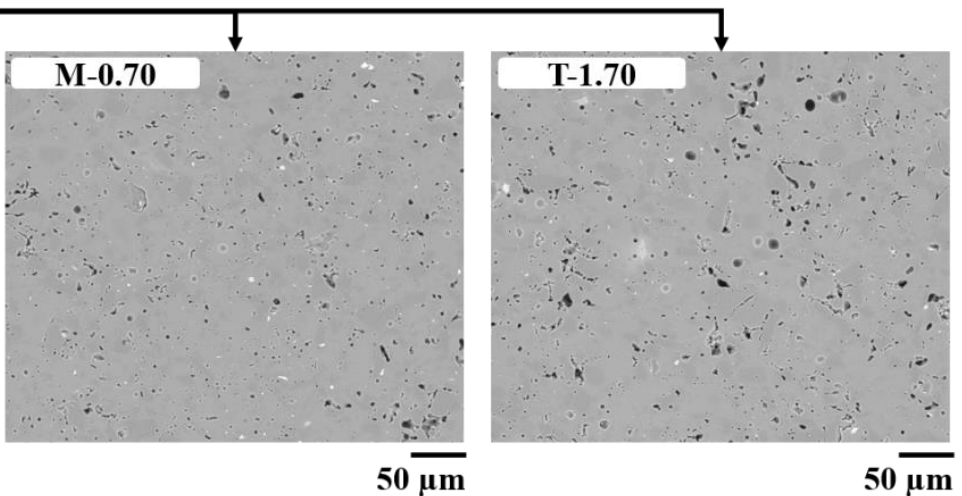

$50 \overline{\mu \mathrm{m}}$

Figure 12. a) Diagram of pyroplasticity index versus water absorption for all the specimens prepared from the four compositions together with the 6-STD composition (shaded zone represents quality requirements for the product in terms of water absorption) b) Cross-section micrographs of fired specimens of the four compositions with additives at the maximum firing density 
A view on the cross-section micrographs of the fired specimens of the four compositions (Figure 12b) fired at the maximum firing density (below $0.5 \%$ of water absorption) also confirm previous findings. Thus, microstructural homogeneity seems to follow the same tendency as that observed with fluxing efficiency, i.e. Magnesite $>$ Talc $>$ Dolomite $\approx$ Calcite. On the one hand, magnesite specimen shows a quite homogeneous microstructure with practically no large pores (higher than $10 \mu \mathrm{m}$ ). On the contrary, dolomite and calcite samples displays more heterogeneous microstructures plenty of large, round pores probably related with an overfiring episode during firing process. This overfiring phenomenon could explain the higher increase in pyroplastic deformation observed when water absorption approaches to zero, in particular for the composition containing dolomite. This is because, due to the lower fluxing efficiencies of these compositions, nearly-zero water absorptions values are obtained with higher firing temperatures which give rise to lower liquid phase viscosities in the last trench of the sintering process and, consequently overfiring and pryroplastic deformation. These findings also confirm the observations by L. Dos Santos et al. when related microstructure homogeneity with pyroplastic deformation [5].

If firing efficiency as shown by reduction of vitrification temperature (Figures 9 and 11) and firing deformation as represented by pyroplastic index variation with water absorption (Figure 12) are considered, it can be concluded that magnesite provides the highest efficiency together with a moderate pyroplastic deformation increase when added to a standard porcelain stoneware tile composition. Talc can be also a good alternative to magnesite [23]. Nevertheless, calcite effect requires high amount of addition which can lead to silicate crystallization retarding vitrification. Finally, dolomite produces a clear narrowing of the firing range as well as a strong increment of pyroplastic index which make this raw material less attractive to be used in industrial practice. 


\section{Conclusions}

The following conclusions can be inferred from this work:

Bulk density exerts a significant effect on pyroplastic deformation. This is because, when bulk density rises, the number of contacts between particles also grows, while pore volume and size of the pressed tile are reduced. All these facts lead to a diminution of the firing temperature to reach a specific water absorption value.

If the bulk density of the pressed bodies is not kept constant increasing grinding time (lowering composition particle size) does not lead to a reduction of pyroplastic deformation despite the decrease of vitrification temperatures that occurs. This is because milling time enhances powder reactivity, but the bulk density of the pressed tile worsens. If the bulk density keeps constant, reduction of composition particle size gives rise to the expected effect on pyroplastic deformation. Thus, the joint effect of particle size and bulk density is of paramount importance to avoid pyroplastic deformation problems. This research emphasizes the need to control these parameters during the manufacturing process.

Four typical fluxing additives were assessed in terms of firing behaviour and pyroplastic deformation. The additives were calcite, dolomite, magnesite and talc. Each fluxing material has been tested at different addition percentage trying to cover the amount used in the industrial practice. It was observed that magnesite provides the highest firing efficiency (decreasing of maximum densification temperature) with a moderate pyroplastic deformation increase. Talc can be also a good alternative to magnesite. However, calcite effect is only observable for high additions and its use can result in crystalline phases development causing vitrification retardation. Dolomite was proved not to be a good candidate as fluxing additive because this material produces a significant narrowing of the firing range as well as a strong increment of pyroplastic index. Some reasons for this unusual dolomite performance are given in the paper.

\section{Acknowledgements}

This research did not receive any specific grant from funding agencies in the public, commercial, or not-for-profit sectors. 


\section{References}

[1] E. Sánchez, J. García-Ten, V. Sanz, A. Moreno, Porcelain tile: Almost 30 years of steady scientific-technological evolution, Ceram. Int. 36 (2010) 831-845.

[2] J.L. Amorós, V. Beltrán, A. Blasco, J.E. Enrique, A. Escardino, F. Negre, Defectos de fabricación de pavimentos y revestimientos cerámicos, first ed., Instituto de Tecnología Cerámica, Castellón, 1991.

[3] C. Zanelli, M. Raimondo, G. Guarini, M. Dondi, The vitreous face of porcelain stoneware: Composition, evolution during sintering and physical properties, J. Non Cryst. Solids 357 (2011) 3251-3260.

[4] E. Sánchez, M.J. Orts, J. García-Ten, V. Cantavella, Porcelain tile composition effect on phase formation and end products, Am. Ceram. Soc. Bull. 80 (2001) 43-49.

[5] L.R. Dos Santos Conserva, F.G. Melchiades, S. Nastri, A.O. Boschi, M. Dondi, G. Guarini, M. Raimondo, C. Zanelli, Pyroplastic deformation of porcelain stoneware tiles: Wet vs dry processing, J. Eur. Ceram. Soc. 37 (2017) 333-342.

[6] D. Magagnin, C.M.F. Dos Santos, A. Wanderlind, J. Jiusti, A. De Noni Jr., Effect of kaolinite, illite and talc on the processing properties and mullite content of porcelain stoneware tiles, Mat. Sci. Eng. A 618 (2014) 533-539.

[7] W.M. Carty, Glass phase composition in porcelains and correlation with pyroplastic deformation, Whitewares Mater. Ceram. Eng. Sci. Proc. 24 (2003) 108-132.

[8] D.Y. Tunçel, E. Özel, Evaluation of pyroplastic deformation in sanitaryware porcelain bodies, Ceram. Int. 38 (2012) 1399-1407.

[9] A. Escardino, J.L. Amorós, F. Negre, C. Felíu, Influence of process parameters on the planarity of floor tiles, Interbrick 5 (1989) 26-31.

[10] A. Barba, V. Beltrán, C. Felíu, J. García-Ten, F. Ginés, E. Sánchez, V. Sanz, Materias primas para la fabricación de soportes de baldosas cerámicas, second ed., Instituto de Tecnología Cerámica, Castellón, 2002.

[11] A.M. Bernardin, D.S. de Medeiros, H.G. Riella, Pyroplasticity in porcelain tiles, Mat. Sci. Eng. A 427 (2006) 316-319.

[12] A. Bresciani, B. Spinelli, Porcelain tile pyroplastic deformation during firing and post-firing variations of planarity, CFI Ceram. Forum Int. 89 (2012) E41-E45. 
[13] J.L. Amorós, E. Sánchez, J. García-Ten, V. Sanz, M. Monzó, Manual para el control de calidad de materias primas arcillosas, first ed., Instituto de Tecnología Cerámica-AICE, Castellón, 1998.

[14] V. Bagán, J.E. Enrique, G. Mallol, E. Sánchez, Influence of process variables on the quality of impervious tiles, Tile \& Brick Int. 6 (1990) 35-42.

[15] J.L. Amorós, M.J. Orts, J. García-Ten, A. Gozalbo, E. Sánchez, Effect of the green porous texture on porcelain tile properties, J. Eur. Ceram. Soc. 27 (2007) 2295-2301.

[16] E. Sánchez, J. García-Ten, A. Barba, C. Felíu, Effect of porcelain tile raw materials composition on pressing behavior of the resulting spray-dried powder, Ceram. Acta, 12 (2000) 18-30.

[17] J.M. Fernández Navarro, El vidrio, third ed., Consejo Superior de Investigaciones Científicas, Madrid, 2003.

[18] Z. Shan, C. Li, H. Tao, Mixed alkaline-earth effect on the mechanical and rheological properties of Ca-Mg silicate glasses, J. Am. Ceram. Soc. 100 (2017) $4570-4580$.

[19] E. Sánchez, J. García, V. Sanz, E. Ochandio, Raw material selection criteria for the production of floor and wall tiles, Tile \& Brick Int. 6 (1990) 15-21.

[20] J.L. Amorós, A. Escardino, E. Sánchez, F. Zaera, Stabilità delle dimensioni nelle piastrelle porose monocotte, Ceram. Inf. 324 (1993) 56-67.

[21] M.U. Taskiran, N. Demirkol, A. Capoglu, A new porcelainised stoneware material based on anorthite, J. Eur. Ceram. Soc. 25 (2005) 293-300.

[22] N.T. Selli, Development of anorthite based white porcelain stoneware tile compositions, Ceram. Inter. 41 (2015) 7790-7795.

[23] V. Biasini, M. Dondi, G. Guarini, M. Raimondo, A. Argnani, S. di Primio, Effect of talc and chlorite on sintering and technological behaviour of porcelain stoneware tiles, Sil. Ind. 68 (2003) 67-73.

[24] F. Güngör, Investigation of pyroplastic deformation of whitewares: Effect of crystal phases in the ' $\mathrm{CaO}$ ' based glassy matrix, Ceram. Inter. 44 (2018) 13360-13366.

[25] A.P. Luz, S. Ribeiro, Use of glass waste as a raw material in porcelain stoneware tile mixtures, Ceram. Inter. 33 (2007) 761-765. 
[26] F. Andreola, L. Barbieri, E. Karamanova, I. Lancellotti, M. Pelino, Recycling of CRT panel glass as fluxing agent in the porcelain stoneware tile production, Ceram. Inter. 34 (2008) 1289-1295.

[27] M. Raimondo, C. Zanelli, F. Matteucci, G. Guarini, M. Dondi, J.A. Labrincha, Effect of waste glass (TV/PC cathodic tube and screen) on technological properties and sintering behaviour of porcelain stoneware tiles, Ceram. Inter. 33 (2007) $615-623$.

[28] T. Aydin, A. Kara, Effect of spodumene addition on pyroplastic deformation of porcelain stoneware, J. Ceram. Proc. Res. 15 (2014) 486-491.

[29] E. Rambaldi, W.M. Carty, A. Tucci, L. Esposito, Using waste glass as a partial flux substitution and pyroplastic deformation of a porcelain stoneware tile body, Ceram. Inter. 33 (2007) 727-733. 